\title{
Mapeando e mensurando o grau de dependência informacional interna dos profissionais de inteligência de marketing: o caso da empresa ALFA
}

Paulo Henrique de Oliveira

Professor do Instituto Federal Minas Gerais (IFMG). outorando em Administração pelo Centro de Pós-Graduação e Pesquisas em Administração (CEPEAD/UFMG) na linha de Pesquisa, Mercadologia e Administração Estratégica.

Carlos Alberto Gonçalves

Doutor em Administração pela Universidade de São Paulo. Professor Associado da Universidade Federal de Minas Gerais (UFMG) e FUMEC.

Edmar Aderson Mendes de Paula

Professor e coordenador da faculdade Pitágoras, no curso de Engenharia Mecânica e Gerente de Marketing do Produto da CNH LATIN AMERICA LTDA.

Apresenta os resultados de um estudo de caso descritivo, realizado em uma grande empresa do setor de máquinas de construção de Minas Gerais, a qual foi intencionalmente selecionada, e os dados foram coletados por meio da aplicação de questionários estruturados a todos os profissionais de inteligência de marketing do respectivo empreendimento. Os resultados evidenciaram que os profissionais de inteligência de marketing têm alta dependência informacional em relação aos departamentos de Marketing, Vendas e Centros de Informação, em comparação aos demais departamentos da empresa. Também ficou clara a relação entre frequência de uso das fontes de informação com o grau de importância atribuído pelos usuários.

Palavras-chave: Dependência Informacional Interna; Inteligência de Marketing; Estudo de Caso Descritivo. 


\title{
Mapping and measuring the degree of internal informational dependence of marketing intelligence professionals: the case of the ALFA company
}

\begin{abstract}
The article presents the results of a descriptive case study conducted in a large company in the construction machinery of Minas Gerais. The company was intentionally selected and data were collected through structured questionnaires and applied to all marketing intelligence professionals. The results showed that marketing intelligence professionals have high informational dependence from the departments of marketing, sales and information centers, compared to other departments. The relationship between frequency of use of information sources with the degree of importance attributed by the users was also clear.
\end{abstract}

KEYWORDS: Dependency Informational Internal; Marketing Intelligence; Descriptive Case Study.

Recebido em 04.09.2009 Aceito em 01.06.2011

\section{Introdução}

O aumento da complexidade e da dinamicidade do ambiente de negócios tem proporcionado desafios crescentes para os gestores contemporâneos, especialmente para aqueles ligados às atividades estratégicas de marketing (KOTLER, 2000). Fatores como globalização econômica, avanços tecnológicos, fusões, aquisições e, principalmente, mudanças no comportamento de compra dos consumidores, percebidas nestas últimas décadas, têm sido frequentemente referenciados na literatura, como algumas das principais causas do aumento da incerteza ambiental.

Neste novo cenário competitivo, que toma forma neste início do século XXI, fatores como flexibilidade, rapidez e inovação contínua em bens e serviços, disponibilizados pelas organizações aos seus mercados consumidores, assumem papéis de destaque, como importantes fontes de vantagens competitivas, além de contribuir para a sobrevivência e o crescimento das organizações nos mercados em que atuam ao longo do tempo (PORTER, 1985; MINTZBERG et al., 2006; BARNEY; CLARK, 2007). Assim, para que os profissionais da área de inteligência de marketing produzam informações estratégicas de mercado úteis para os altos 
executivos, torna-se necessário que os mesmos identifiquem fontes de informações capazes de fornecer informações mais precisas, relevantes, oportunas, instantâneas e confiáveis sobre fatos, eventos, tendências e relacionamentos percebidos no ambiente de negócios, onde a organização está inserida (KOTLER, 2000).

Nesta perspectiva, partindo-se do pressuposto da importância da informação de qualidade para a eficácia da tomada de decisão ( $\mathrm{CHOO}$, 2003), especialmente no contexto do marketing (KOTLER, 2000), este artigo apresenta os resultados de um estudo de caso descritivo, realizado em uma grande empresa multinacional do setor de máquinas de construção, instalada em Minas Gerais. Para mapear e mensurar o grau de dependência informacional do departamento de Inteligência de Marketing, em relação aos demais departamentos do respectivo empreendimento, foi adaptado um modelo de análise de dependência informacional desenvolvido por Oliveira (2009). Os dados foram coletados através da aplicação de questionários estruturados a todos os profissionais do Departamento de Inteligência de Marketing e processados por meio de técnicas da estatística descritiva.

Estruturalmente, este artigo está assim organizado: na primeira parte, são apresentados o objetivo de pesquisa e a justificativa da mesma. Na segunda parte, temas como informação e tomada de decisão e sistema de inteligência de marketing são analisados. Na terceira parte, são descritos os procedimentos metodológicos utilizados para a consecução do objetivo proposto. Na quarta parte, os dados são processados e analisados. Na quinta e última parte, algumas conclusões são expostas e recomendações para futuras pesquisas são sugeridas.

Espera-se, com esta pesquisa, contribuir para o melhor entendimento das relações informacionais existentes entre 0 departamento responsável pela atividade de inteligência de marketing e os demais departamentos da organização. Neste estudo, foram consideradas apenas fontes internas de informação, porque as mesmas estão dentro da organização e podem ser controladas diretamente por ela, fato este que não exclui a importância das fontes externas de informação para o processo de geração de inteligência de marketing, podendo ser exploradas em pesquisas futuras.

Importante destacar que um trabalho de inteligência de marketing de qualidade deve considerar tanto fontes internas quanto fontes externas de informações e que a eficácia do processo de coleta das informações necessárias vai depender da habilidade do profissional de inteligência de marketing em selecionar as fontes de informações adequadas e mantê-las constantemente disponíveis para o fornecimento contínuo e instantâneo de informações úteis para a tomada de decisão em marketing (FULD, 1995; KAHANER, 1996; GRZANKA, 1999; HERRING, 1999; MILLER, 2002).

\section{Suporte teórico}




\subsection{Informação e tomada de decisão}

É consenso, entre grande parte dos teóricos da ciência da administração, de que a tomada de decisão nas organizações requer informações exatas, oportunas e confiáveis capazes de reduzir o nível de incerteza em um determinado contexto decisório. Choo (2003), por exemplo, tem argumentado que a informação pode reduzir a incerteza no processo decisório de três maneiras principais: (i) estruturando uma situação de escolha; (ii) definindo preferências e selecionando regras; e (iii) fornecendo informações sobre as alternativas viáveis e as suas possíveis consequências. Estas maneiras de se reduzir a incerteza na tomada de decisão podem ser melhor compreendidas a partir dos estudos de Simon (1971), sobre as etapas do processo decisório. O QUADRO 1 destaca a necessidade, busca e uso da informação na tomada de decisão organizacional.

QUADRO 1 - Nessidades, busca e uso da informação na tomada de decisões

\begin{tabular}{c|c|c|c}
\hline & $\begin{array}{c}\text { Necessidade de } \\
\text { informação }\end{array}$ & Busca de Informação & Uso da informação \\
\hline $\begin{array}{c}\text { Tomada de } \\
\text { Decisões }\end{array}$ & $\begin{array}{c}\text { Esclarminar a estrutura } \\
\text { e os limites do } \\
\text { problema. } \\
\text { e adequação da regra. } \\
\text { Informações sobre } \\
\text { alternativas, resultados, } \\
\text { preferências. }\end{array}$ & $\begin{array}{c}\text { Guiada por princípios } \\
\text { heurísticos e hábitos. } \\
\text { Busca motivada por } \\
\text { problema. } \\
\text { Critérios para uma } \\
\text { solução satisfatória. }\end{array}$ & $\begin{array}{c}\text { Limitações no } \\
\text { processamento da } \\
\text { informação. } \\
\text { Estruturado por rotinas } \\
\text { e regras. } \\
\text { Muitos problemas } \\
\text { competem por atenção. }\end{array}$ \\
\hline
\end{tabular}

Fonte: adaptado de CHOO (2003, p. 303).

Antes de se aprofundar na questão da importância da informação para a tomada de decisão, torna-se necessário explicar o que significa o termo "informação" e o seu tratamento nas organizações contemporâneas, como recurso estratégico gerenciável e capaz de proporcionar vantagens competitivas.

Em termos conceituais, Davenport e Prusak (1998, p. 4) definem a informação como uma "mensagem, geralmente na forma de um documento ou uma comunicação audível ou visível [...] ela tem um emitente e um receptor". Para estes autores, a informação tem por finalidade mudar o modo de como o destinatário vê algo; e exercer algum impacto sobre seu julgamento e comportamento. Etimologicamente, a palavra informação vem do verbo informar (dar forma a) e visa modelar pessoas, que a recebe no sentido de fazer alguma diferença em sua perspectiva ou insight. Normalmente, a informação se movimenta pela organização, através de sua infraestrutura de tecnologia da informação e 
da comunicação (hardware e software). Neste sentido, percebem-se diferenças substanciais entre dado e informação. Segundo Davenport e Prusak (1998), a informação diferencia-se dos dados por que ela tem significado, dando forma ao receptor a partir da sua forma e objetivo determinados. Assim, os dados tornam-se informação quando o seu criador Ihes acrescenta significado. Esses autores apontam cinco métodos diferentes que as pessoas podem utilizar para transformar dados em informações, conforme demonstrado a seguir (DAVENPORT; PRUSAK, 1998, p.3):

Contextualização: saber qual a finalidade dos dados coletados;

Categorização: conhecer as unidades de análise ou os componentes essenciais dos dados;

Cálculo: os dados podem ser analisados matemática ou estatisticamente;

Correção: os erros são eliminados dos dados; e

Condensação: os dados podem ser resumidos para uma forma mais concisa.

Os autores ainda ressaltam a importância de se considerar os computadores no processo de transformação dos dados em informações, mas advertem, porém, que eles quase nunca ajudam na parte de contexto e os seres humanos geralmente precisam agir nas partes de categorização, cálculo e condensação (DAVENPORT; PRUSAK, 1998).

Retornando-se à discussão central deste item, sobre a importância da informação para a tomada de decisão, Choo (2003) ainda analisa a informação como um componente intrínseco de quase tudo que uma organização faz. Para este autor, os tomadores de decisões usam a informação para dar sentido às mudanças do ambiente externo, para gerar novos conhecimentos por meio da aprendizagem organizacional (criação, organização e processamento da informação) e para avaliar os processos de tomada de decisão que são importantes para a sobrevivência e o crescimento da organização no ambiente em que elas estão inseridas. Marchand, Kettinger e Rollins (2001), por outro lado, defendem uma posição mais estratégica da informação, focando-se em entender como a informação é ou deveria ser usada na empresa, para potencializar o desempenho empresarial, sem negligenciar o papel das pessoas nesse processo, visão esta também defendida por Davenport e Prusak (1998). Barbosa, porém, (2006, p. 92) adverte:

Do ponto de vista da prática gerencial, são inúmeros os desafios encontrados pelos profissionais para se informarem a respeito do que acontece no entorno de suas empresas. Por um lado, é difícil selecionar, dentre a crescente multiplicidade de fontes de informação existentes, aquelas que contêm, de fato, o que se necessita. Por outro lado, a farta disponibilidade 
de informações não assegura, em si, que elas sejam efetivamente valiosas para seus usuários (BARBOSA, 2006, p. 92).

Em uma perspectiva teórica e evolucionista, ainda é importante destacar algumas vertentes teóricas que tratam a informação como um recurso organizacional estratégico (BERGERON, 1996; SAVIC, 1992). Para estes autores, a informação deve ser vista como um recurso, como qualquer outro (financeiro, humano, material), que precisa ser gerenciado e organizado, pois ela ajuda as organizações a aumentarem a sua produtividade, competitividade e desempenho.

Em relação à troca de informação entre os departamentos organizacionais, Choo (2003) ainda adverte que a disponibilidade e acessibilidade da informação são influenciadas por muitos aspectos institucionais, em especial, as estruturas organizacionais que regulam o fluxo de informação e os sistemas de incentivo que atribuem valor e preferência à consecução de certos objetivos e informações. Para este autor, a hierarquia e a especialização são meios tradicionais pelos quais as organizações aumentam a sua capacidade de processar informações com o objetivo de satisfazer os requisitos de desempenho (CHOO, 2003).

Com o crescente uso da informação na tomada de decisão é importante considerar as fontes que geram e disponibilizam tais informações. No que se refere ao tema "fontes de informações", é consenso entre os teóricos desta vertente do conhecimento, de que existe uma infinidade de classificações e estudos sobre este assunto na literatura, especialmente entre aquelas ligadas à Ciência da Informação. Pereira e Barbosa (2008), por exemplo, utilizaram o seguinte esquema de classificação em uma pesquisa realizada com 104 consultores, conforme apresentado na FIG. 1.

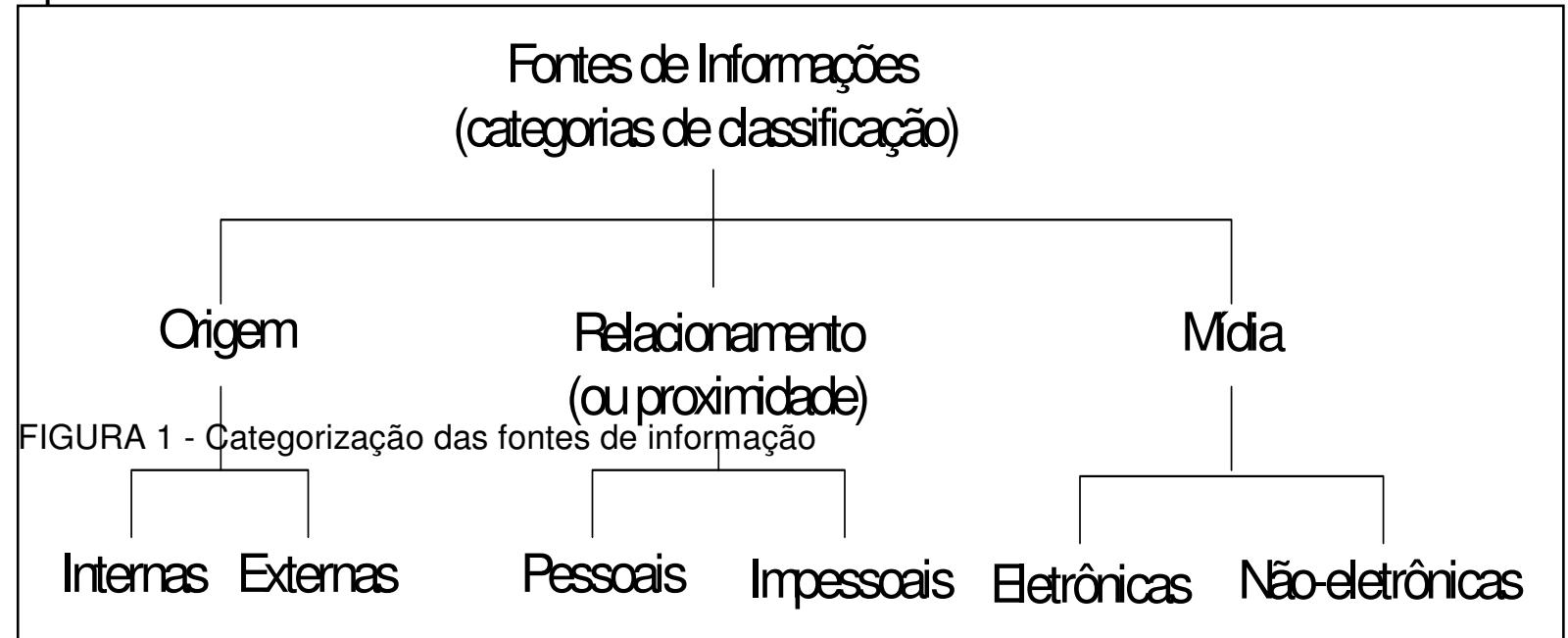

Fonte: adaptado de PEREIRA e BARBOSA (2008, p. 95).

Pereira e Barbosa (2008) chamam as fontes pessoais de informal ou não estruturadas e as fontes impessoais de formais ou estruturadas, as quais são importantes para a busca de informações relevantes de caráter 
documental ou formal. Ainda, segundo estes autores, são exemplos de mídias eletrônicas a internet, a mídia eletrônica propriamente dita, $C D$ ROMs, disquetes e base de dados on-line. Por outro lado, as mídias nãoeletrônicas são aquelas informações que estão documentadas em papéis, como por exemplo, nos relatórios, memorandos e outros documentos organizacionais.

$\mathrm{Na}$ tentativa de categorização das fontes de informação, Daft e Lengel (1986) também classificaram as fontes de informação em interna e externa. Segundo estes autores, algumas fontes de informações externas podem ser os periódicos e jornais da área comercial, amigos na indústria, clientes, entre outros. Internamente, as fontes citadas pelos autores foram as reuniões formais e não agendadas e os passeios pela empresa, entre outras. Borges (1995), por sua vez, complementa os estudos desses autores, ao apresentar algumas das principais fontes de informações que poderão ser utilizadas pelas organizações, como por exemplo, as suas equipes de vendas e de engenharia, os fornecedores, as agências de publicidade, os próprios concorrentes, como, também, as associações comerciais e as empresas de pesquisas mercadológicas, entre outras.

Em relação ao processo de busca de informação, Pereira e Barbosa (2008) apresentam dois subconceitos para explicar o comportamento de busca informacional. O primeiro deles relata que o comportamento de busca por informações é uma consequência de satisfazer uma necessidade e/ou objetivo. O segundo conceito se refere ao termo pesquisa informacional, o qual representa "o nível micro do comportamento do pesquisador em interações mentais, intelectuais envolvendo julgamentos da relevância do dado ou informação recuperada em diversos tipos de sistemas de informação" (PEREIRA; BARBOSA, 2008, p. 98-99). Assim, pode-se dizer que uma informação é útil ou importante para a organização, quando ela tem impacto no alcance dos objetivos e metas organizacionais ou departamentais.

Choo (2003), nesta mesma linha de raciocínio, também reflete sobre a importância da informação para o desempenho organizacional. Para este autor, toda informação deve atender a um ou vários objetivos organizacionais, podendo ser agrupadas em três campos ou arenas: a primeira delas aborda a necessidade de interpretação da informação para dar significado ao que está acontecendo com a empresa em um determinado ambiente; na segunda, o autor ressalta a importância da informação para gerar novos conhecimentos e, por último, a organização processa e analisa a informação para a orientação de seus processos de tomada de decisão. Essas três arenas são interdependentes e dão sentido ao conceito de visão holística do uso da informação (CHOO, 2003).

Ao se tratar dos temas informação e tomada de decisão, é importante analisar as barreiras que podem ocorrer na comunicação da informação. Starec, Gomes e Bezerra (2005), por exemplo, advertem que essas barreiras não são estáticas e nem fixas, elas são móveis e perpassam todas as áreas, podendo ser encontradas separadas ou de forma simultânea. Dentre as principais barreiras apontadas por esses 
autores têm-se: a má comunicação, derivada da falta de diálogo constante; a cultura organizacional, a qual deve respaldar o fluxo informacional, estimulando e dando acesso à informação; a falta de competência das pessoas e a dependência tecnológica como barreira à comunicação da informação. Para os autores, o valor da tecnologia da informação depende da informação e do papel desempenhado por ela nas organizações e que a logística da organização deve ser pensada para que a informação possa fluir por todos os setores envolvidos, circulando livremente pela organização, para que forneça os insumos necessários para uma tomada de decisão cada vez mais eficaz.

Como analisado até o presente momento, percebe-se que a informação é um importante recurso para a organização, especialmente para o processo de tomada de decisão. Para reduzir riscos e incertezas, é importante que a organização esteja sempre atenta às barreiras que possam interferir no processo de comunicação da informação. Desta forma, estar atento à cultura organizacional, às competências das pessoas, a um melhor processo de comunicação, com total suporte das tecnologias da informação e da comunicação, parece ajudar a melhorar o fluxo informacional dentro da organização, proporcionando melhores condições para uma tomada de decisão cada vez mais eficiente e eficaz (DRUCKER, 1995).

Finalmente, conclui-se que a seleção e o uso apropriado de fontes de informações, tanto internas quanto externas, podem ajudar os executivos, especialmente aqueles ligados aos departamentos de marketing e de administração estratégica, a tomarem melhores decisões de curto, médio ou longo prazos. Nesta perspectiva, manter um processo de monitoramento contínuo dos ambientes interno e externo pode ajudar os tomadores de decisões a descobrirem pontos fortes e fracos da organização, como, também, ajudar a evitar ou reduzir ameaças e surpresas desagradáveis. Além disto, propicia a obtenção de oportunidades de negócios, que possibilitam melhores condições para a sobrevivência e o crescimento das organizações nos mercados em que atuam, em tempos de grande hostilidade e turbulência competitiva.

\subsection{Sistema de inteligência de marketing}

Existe um consenso na literatura, especialmente entre grande parte dos autores que pesquisam sobre o tema estratégia, de que o ambiente de negócios do início deste século XXI, está cada vez mais complexo, dinâmico e imprevisível. Para muitos destes autores, dentre eles destacam-se Porter (1980; 1985), D'Aveni (1995), Hitt, Ireland e Hoskisson (2003), Mintzberg et al. (2006), Barney e Hesterly (2007), entra-se em uma era determinada por incertezas, onde a sobrevivência e o crescimento das organizações, nos mercados em que atuam ao longo do tempo, dependerão, dentre outras coisas, das suas capacidades de se ajustarem com maior rapidez e eficácia às crescentes ameaças e oportunidades impostas por seus ambientes em crescente transformação. 
Com o crescimento e a modernização da competição, percebidos em praticamente todos os setores econômicos mundiais, acadêmicos e empresários do mundo todo têm voltado as suas atenções para um novo processo organizacional: a Inteligência Competitiva (IC). Barbosa (2006, p.92), por exemplo, argumenta que "ao lado das implicações práticas desse contexto de complexidade e mudanças para os gerentes, que precisam tomar decisões bem informadas para o benefício de suas empresas, o mundo acadêmico encontra, no contexto da inteligência competitiva, um campo fértil para investigações".

Entendida como um processo legal e ético de coleta e análise de dados e informações sobre o ambiente competitivo, para posterior disponibilização dos mesmos na forma de produtos de inteligência para os gestores da alta cúpula (KAHANER, 1996; MILLER, 2002), a IC tem assumido cada vez mais um papel estratégico para as organizações contemporâneas e ocupado a agenda dos teóricos organizacionais, na medida em que se reconhece a importância da mesma para os processos de formulação e implementação de estratégias competitivas em setores determinados por acirrada competição (FULD, 1995; MILLER, 2002). Para Barbosa (2006), a grande parte das pesquisas realizadas sobre IC tem focalizado as grandes empresas. No Brasil, conforme destaca o autor, a IC também é conhecida por inteligência empresarial e normalmente está associada com os processos de monitoramento ambiental e gestão do conhecimento (BARBOSA, 2006). A FIG. 2 destaca as principais etapas de um processo de IC.

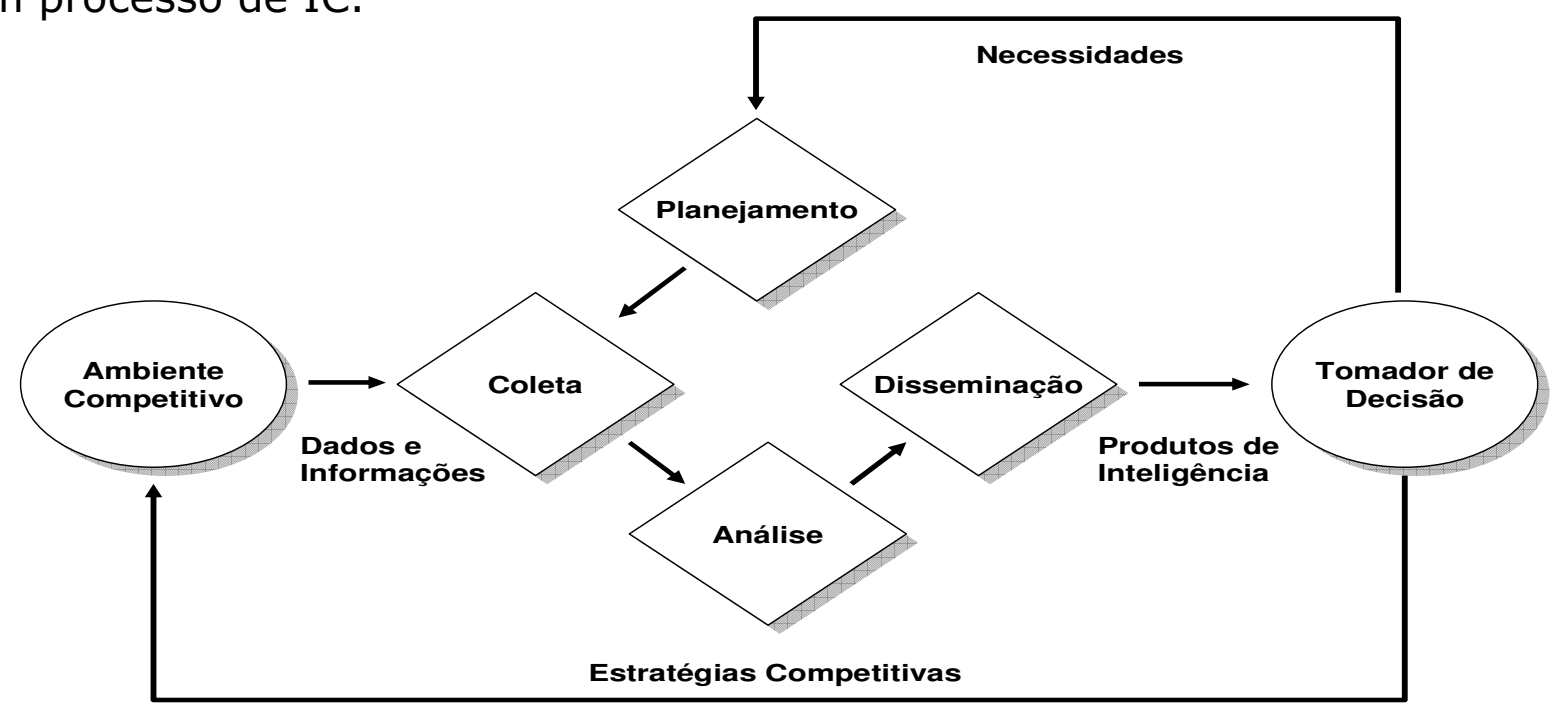

FIGURA 2 - Visão sistêmica da IC

Fonte: Elaborado pelos autores.

Kotler (2000) também reconhece que o ambiente está mudando a um ritmo cada vez mais acelerado, o que tem gerado a necessidade de informações de mercado em tempo real. Para este autor, a medida que as organizações expandem sua cobertura geográfica de mercado, seus 
gestores precisam de informações cada vez mais rápidas, precisas e de qualidade. $O$ autor discute o processo de coleta de informações, no contexto do marketing, a partir da análise de cinco elementos principais: sistema de informações de marketing, sistema de registros internos, sistema de inteligência de marketing, sistema de pesquisa de marketing e sistema de apoio à decisão de marketing. Nesta discussão, será considerado apenas o sistema de inteligência de marketing, por motivo de coerência com o objetivo de pesquisa proposto.

Em termos teóricos, um sistema de inteligência de marketing pode ser definido, conforme as palavras de Kotler (2000, p. 124), como "um conjunto de procedimentos e fontes usado por administradores para obter informações diárias sobre eventos no ambiente de marketing". Para este autor, os profissionais de marketing normalmente coletam informações de marketing através da leitura de livros, jornais e publicações setoriais, como, também, conversando com clientes, fornecedores e distribuidores, além de participar de reuniões com administradores de outras empresas.

Estruturalmente, o sistema de inteligência de marketing pode compreender vários passos, onde os profissionais responsáveis pelas atividades de inteligência de marketing têm como atribuições principais KOTLER (2000, p.124-125):

a) Treinar e motivar o pessoal de vendas para que localize e relate novos acontecimentos;

b) Motivar distribuidores, revendedores e outros intermediários a repassar alguma informação importante;

c) Aprender sobre concorrentes, comprando seus produtos, comparecendo à inauguração e demonstrações, lendo os relatórios publicados sobre o concorrente, comparecendo a reuniões de acionistas, conversando com funcionários, revendedores, distribuidores, fornecedores e transportadores do concorrente, buscando anúncios do concorrente e lendo jornais especializados ou boletins de associações comerciais e setoriais;

d) Promover um painel consultivo de clientes composto de clientes representativos dos maiores clientes da empresa ou de seus mais francos e experientes clientes;

e) Comprar informações de fornecedores externos (institutos de pesquisas); e

f) Estabelecer um centro de informações de marketing para coletar e disseminar informações de marketing.

Nesta perspectiva, com o aumento da incerteza do ambiente de negócios, torna-se necessário que os profissionais de marketing contem com informações estratégicas e instantâneas de qualidade sobre os seus mercados consumidores e competidores, na tentativa de evitarem 
surpresas desagradáveis, que coloquem em risco o desempenho das organizações onde trabalham. E, neste contexto, a estruturação de um sistema de inteligência de marketing pode ajudar os altos executivos na consecução de estratégias competitivas, que proporcionem vantagens competitivas e retornos superiores em relação aos concorrentes, nos mercados onde as organizações atuam ao longo do tempo.

\section{Procedimentos metodológicos}

\subsection{Estratégia de pesquisa}

Para a consecução do objetivo proposto, optou-se pela utilização do estudo de caso descritivo como estratégia de pesquisa, cujo objetivo principal, segundo Collins e Hussey (2005) está restrito a descrever a prática corrente. Por outro lado, o estudo de caso, nas palavras de Laville e Dionne (1999, p.154), "permite, inicialmente, fornecer explicações no que tange diretamente ao caso considerado e elementos que lhe marcam - contexto". Para estas autoras, a vantagem mais marcante dessa estratégia de pesquisa refere-se à possibilidade de aprofundamento que a mesma oferece, pois, os recursos e as variáveis de determinados fenômenos estão concentrados no caso visado, não estando o estudo submetido às restrições ligadas à comparação do caso com outros casos.

Esta abordagem também é contemplada por Greenwood (1973) e Yin (2001), ao defenderem a questão do exame intensivo de uma unidade de análise que o estudo de caso proporciona. Conforme argumentam estes autores, o estudo de caso permite verificar características de eventos da vida real com maior profundidade, abordando-os de maneira clara, sendo uma estratégia apropriada a estudos de processos gerenciais e organizacionais, por adotar um aspecto mais qualitativo do que quantitativo, o que é o caso desta pesquisa.

Cabe, ainda, ressaltar que por limitar-se a uma única realidade, os resultados obtidos no estudo de caso podem apresentar consistência interna, mas deixam a desejar quando generaliza, uma vez que as conclusões não podem ser inferidas para todo tipo de organização e que, estes resultados, podem não ser verificados sob certas condições.

\subsection{Modelo adaptado para a mensuração do grau de dependência informacional}

Para a mensuração do grau de dependência informacional dos profissionais de inteligência de marketing, foram considerados dois construtos: (a) frequência de uso das fontes de informações para a consecução dos produtos de inteligência de marketing; e (b) importância das mesmas, conforme a percepção dos profissionais do departamento de inteligência de marketing. O QUADRO 2 apresenta os construtos e as escalas (tipo Likert) utilizadas para mensurar o grau de dependência 
informacional dos profissionais de inteligência de marketing na consecução de suas atividades laborais.

QUADRO 2 - Estrutura para mensurar o grau de dependência informacional dos profissionais de inteligência de marketing

\begin{tabular}{|c|c|c|c|c|c|c|c|c|c|c|}
\hline \multirow{3}{*}{$\begin{array}{c}\text { Fontes Internas } \\
\text { de Informação } \\
\text { (Departamento } \\
\text { s) }\end{array}$} & \multicolumn{5}{|c|}{ FREQUÊNCIA DE USO } & \multicolumn{5}{|c|}{ IMPORTÂNCIA PERCEBIDA } \\
\hline & \multicolumn{5}{|c|}{ Baixíssima -------------------Altíssima } & \multicolumn{5}{|c|}{$\begin{array}{c}\text { Baixíssima -------------- } \\
\text { Altíssima }\end{array}$} \\
\hline & 1 & 2 & 3 & 4 & 5 & 1 & 2 & 3 & 4 & 5 \\
\hline Depto A & 0 & 0 & $\mathrm{O}$ & 0 & 0 & 0 & 0 & 0 & 0 & $\mathrm{O}$ \\
\hline Depto B & $\mathrm{O}$ & $\mathrm{O}$ & $\mathrm{O}$ & $\mathrm{O}$ & $\mathrm{O}$ & $\mathrm{O}$ & $\mathrm{O}$ & $\mathrm{O}$ & O & $\mathrm{O}$ \\
\hline Depto C & $\mathrm{O}$ & $\mathrm{O}$ & $\mathrm{O}$ & $\mathrm{O}$ & $\mathrm{O}$ & $\mathrm{O}$ & $\mathrm{O}$ & $\mathrm{O}$ & O & 0 \\
\hline Depto D & 0 & 0 & 0 & 0 & 0 & O & 0 & 0 & 0 & 0 \\
\hline Depto $n$ & 0 & 0 & 0 & 0 & 0 & 0 & 0 & 0 & 0 & 0 \\
\hline
\end{tabular}

Fonte: adaptado de OLIVEIRA (2009, p. 219).

\subsection{Unidade de análise}

A empresa ALFA é uma grande empresa do setor de máquinas de construção, atua em Minas Gerais, desde o ano de 1969. Atualmente, comercializa produtos como Escavadeiras Hidráulicas, Pás-carregadeiras, Retroescavadeiras, Mononiveladores, entre outros, para os mercados de terraplanagem e construção em geral. Conta com mais de 750 funcionários diretos, os quais estão alocados em Minas Gerais e São Paulo.

Em termos financeiros, o faturamento mundial bruto anual da empresa, envolvendo as áreas agrícolas e de construção, gira em torno de U\$ 17 bilhões, valores referentes ao ano de 2008. Em relação ao seu mercado competitivo, devido ao número de empresas nacionais concorrentes e ao crescimento constante de máquinas importadas de fabricantes, atraídos pela oportunidade criada pela situação cambial e crescimento de mercado, faz-se necessária a adoção de práticas relacionadas à Inteligência Competitiva. Assim, para manter-se constantemente atualizada em relação ao seu ambiente competitivo, a empresa ALFA estruturou o seu departamento de Inteligência de Marketing há mais de 10 anos. Atualmente, este departamento conta com quatro profissionais altamente qualificados, com experiência média em torno de cinco anos em atividades de inteligência, os quais estão diretamente subordinados ao setor de Marketing e Inteligência de Mercado.

Para mais detalhes, o QUADRO 3 resume, então, algumas das principais características dos profissionais de inteligência de marketing que responderam os questionários durante a pesquisa de campo.

QUADRO 3 - Características principais dos profissionais do departamento de Inteligência de Marketing da empresa ALFA 


\begin{tabular}{c|c|c|c}
\hline $\begin{array}{c}\text { PROFISSIONAIS DO } \\
\text { DEPARTAMENTO DE IC }\end{array}$ & SEXO & $\begin{array}{c}\text { FORMAÇÃO } \\
\text { ACADÊMICA }\end{array}$ & $\begin{array}{c}\text { TEMPO DE EXPERIÊNCIA EM } \\
\text { ATIVIDADES DE INTELIGÊNCIA }\end{array}$ \\
\hline A & M & Mestrado & 4 anos \\
\hline B & M & Especialização & 5 anos \\
\hline C & F & Especialização & 6 anos \\
\hline D & F & Especialização & 5 anos \\
\hline
\end{tabular}

Fonte: dados da pesquisa.

\subsection{Técnicas de coleta e análise dos dados}

A coleta de dados foi realizada através da aplicação de questionários estruturados (perguntas fechadas) a todos os profissionais do departamento de inteligência de marketing. O tempo gasto com cada profissional de inteligência foi de aproximadamente 45 minutos, perfazendo um total de 180 minutos (ou 3 horas). Importante destacar que, antes da aplicação dos questionários, foi feito um pré-teste com o gerente responsável pelo respectivo departamento, aqui chamado de profissional A, conforme demonstrado no QUADRO 3.

Nos questionários aplicados, foram consideradas questões relativas à frequência de uso e grau de importância de determinadas fontes internas de informações para a consecução das atividades de inteligência de marketing realizadas pelo respectivo departamento. A coleta de dados ocorreu no mês de abril de 2009.

Para o tratamento e análise dos dados coletados foram, construídas escalas de mensuração (ver QUADRO 2) e utilizadas técnicas de análise exploratória (estatística descritiva), para verificar a dependência informacional dos profissionais de inteligência de marketing em relação às fontes de informações internas utilizadas por eles.

\section{Apresentação e análise dos dados}

\subsection{Da frequência de uso}

Para a mensuração do grau de dependência informacional do profissional de inteligência de marketing, torna-se necessário identificar a frequência com que os mesmos usam determinadas fontes de informações para a consecução de suas atividades profissionais. Nesta pesquisa, foi considerada a seguinte escala para mensuração deste construto: 1 menos de duas vezes por semana; 2 - entre três e quatro vezes por semana; 3 - entre 5 e 8 vezes por semana; 4 - entre 9 e 13 vezes por semana; e 5 - acima de 14 vezes por semana. Estes valores foram definidos em comum acordo com os profissionais da área de marketing. Os dados dos questionários aplicados estão resumidos na TAB. 1 a seguir. 
TABELA 1 - Frequência de uso das fontes de informações internas, conforme respostas dos profissionais de inteligência de marketing da empresa ALFA

\begin{tabular}{c|c|c|c|c}
\hline $\begin{array}{c}\text { FONTES } \\
\text { INTERNAS DE } \\
\text { INFORMAÇÃO }\end{array}$ & \multicolumn{4}{|c}{$\begin{array}{c}\text { RESPOSTAS DOS PROFISSIONAIS DO DEPARTAMENTO DE } \\
\text { INTELIGÊNCIA DE MARKETING - FREQUÊNCIA DE USO }\end{array}$} \\
\cline { 2 - 5 } & Profissional A & Profissional B & Profissional C & Profissional D \\
\hline Engenharia & 2 & 1 & 1 & 4 \\
\hline Finanças & 2 & 4 & 4 & 5 \\
\hline Recursos Humanos & 1 & 1 & 1 & 2 \\
\hline $\begin{array}{c}\text { Centros de } \\
\text { Informação }\end{array}$ & 3 & 5 & 3 & 5 \\
\hline Produção & 3 & 1 & 1 & 3 \\
\hline Marketing & 4 & 5 & 5 & 5 \\
\hline Suprimentos & 4 & 1 & 1 & 4 \\
\hline Relações Públicas & 2 & 2 & 4 & 3 \\
\hline P\&D & 4 & 1 & 4 & 5 \\
\hline Vendas & 5 & 4 & 5 & \\
\hline
\end{tabular}

Fonte: dados da pesquisa.

Com base nos dados da TAB. 1, foi calculado o valor médio das respostas dadas pelos profissionais de inteligência de marketing em relação ao uso das fontes internas de informação. A TAB. 2 apresenta as médias aritméticas calculadas.

TABELA 2 - Valor médio da frequência de uso das fontes de informações internas, conforme respostas dos profissionais de inteligência de marketing da empresa ALFA

\begin{tabular}{c|c}
\hline FONTES INTERNAS DE INFORMAÇÃO & $\begin{array}{c}\text { VALORES MÉDIOS DAS RESPOSTAS } \\
\text { (Frequência de Uso) }\end{array}$ \\
\hline Engenharia & 2,0 \\
\hline Finanças & 3,75 \\
\hline Recursos Humanos & 1,25 \\
\hline Centros de Informação & 4,0 \\
\hline Produção & 2,0 \\
\hline Marketing & 4,75 \\
\hline Suprimentos & 2,5 \\
\hline Relações Públicas & 2,75 \\
\hline Pesquisa e Desenvolvimento & 3,0 \\
\hline Vendas & 4,75 \\
\hline
\end{tabular}

Fonte: dados da pesquisa.

De acordo com os dados da TAB. 2, percebe-se que os departamentos de Marketing, Vendas e Centros de Informação são as fontes de internas de informações mais consultadas pelos profissionais de inteligência de marketing. Os departamentos de Finanças e de Pesquisa e Desenvolvimento apresentaram resultados medianos. Por outro lado, os departamentos de Engenharia, Produção, Suprimentos, Relações Públicas e de Recursos Humanos apresentaram resultados pouco expressivos. 
Destaca-se, nesta análise, os baixos valores conferidos aos departamentos de Engenharia e de Produção, o que deve ser melhor investigado por pesquisas futuras sobre o tema em questão.

\subsection{Da importância percebida}

Outro construto considerado na mensuração do grau de dependência informacional do profissional de inteligência de marketing, em relação a uma determinada fonte de informação, é a importância conferida por estes profissionais a essas fontes de informação, para a consecução de suas atividades laborais. Os dados coletados estão disponibilizados na TAB. 3.

TABELA 3 - Grau de importância das fontes de informações internas para a consecução das atividades de inteligência, conforme respostas dos profissionais de inteligência de marketing da empresa ALFA.

\begin{tabular}{c|c|c|c|c}
\hline $\begin{array}{c}\text { FONTES } \\
\text { INTERNAS DE } \\
\text { INFORMAÇÃO }\end{array}$ & \multicolumn{4}{|c}{$\begin{array}{c}\text { RESPOSTAS DOS PROFISSIONAIS DO DEPARTAMENTO DE } \\
\text { INTELIGÊNCIA DE MARKETING - IMPORTÂNCIA PERCEBIDA }\end{array}$} \\
\cline { 2 - 5 } & Profissional A & Profissional B & Profissional C & Profissional D \\
\hline Engenharia & 3 & 3 & 1 & 4 \\
\hline Finanças & 3 & 3 & 4 & 5 \\
\hline Recursos Humanos & 1 & 2 & 1 & 1 \\
\hline $\begin{array}{c}\text { Centros de } \\
\text { Informação }\end{array}$ & 4 & 3 & 4 & 5 \\
\hline Produção & 3 & 2 & 2 & 1 \\
\hline Marketing & 5 & 5 & 5 & 5 \\
\hline Suprimentos & 4 & 2 & 1 & 2 \\
\hline Relações Públicas & 2 & 3 & 5 & 2 \\
\hline P\&D & 4 & 5 & 4 & 5 \\
\hline Vendas & 5 & 5 & 5 & \\
\hline
\end{tabular}

Fonte: dados da pesquisa.

Com base nos dados da TAB. 3, foi calculado o valor médio das respostas dadas pelos profissionais de inteligência de marketing, em relação à importância das fontes internas de informação. A TAB. 4 apresenta as médias aritméticas calculadas.

TABELA 4 - Valor médio da importância percebia em relação ao uso das fontes de informações internas, conforme respostas dos profissionais de inteligência de marketing da empresa ALFA

\begin{tabular}{c|c}
\hline FONTES INTERNAS DE INFORMAÇÃo & $\begin{array}{c}\text { VALORES MÉDIOS DAS RESPOSTAS } \\
\text { (Importância Percebida) }\end{array}$ \\
\hline Engenharia & 2,75 \\
\hline Finanças & 3,75 \\
\hline Recursos Humanos & 1,25 \\
\hline Centros de Informação & 4,0 \\
\hline Produção & 2,0 \\
\hline Marketing & 5,0 \\
\hline
\end{tabular}




\begin{tabular}{c|c}
\hline Suprimentos & 2,5 \\
\hline Relações Públicas & 3,0 \\
\hline Pesquisa e Desenvolvimento & 3,75 \\
\hline Vendas & 5,0 \\
\hline
\end{tabular}

Fonte: dados da pesquisa.

De acordo com os dados da TAB. 4, percebe-se que os departamentos de Marketing, Vendas e Centros de Informações apresentaram as médias mais elevadas. Departamentos como o de Finanças, Pesquisa e Desenvolvimento e de Relações Públicas apresentaram resultados intermediários. Por outro lado, os departamentos de Engenharia, Recursos Humanos, Produção e Suprimentos foram os departamentos que apresentaram os menores valores médios em termos de importância no fornecimento de informações para as atividades de inteligência de marketing, o que, de certa forma, corroboram os resultados obtidos no construto "frequência de uso".

\subsection{Do grau de dependência informacional do departamento de inteligência de marketing}

Com base nos dados das TAB. 2 e 4, a FIG. 3 foi desenvolvida para demonstrar o grau de dependência informacional do departamento de inteligência de marketing, em relação a determinadas fontes internas de informações.

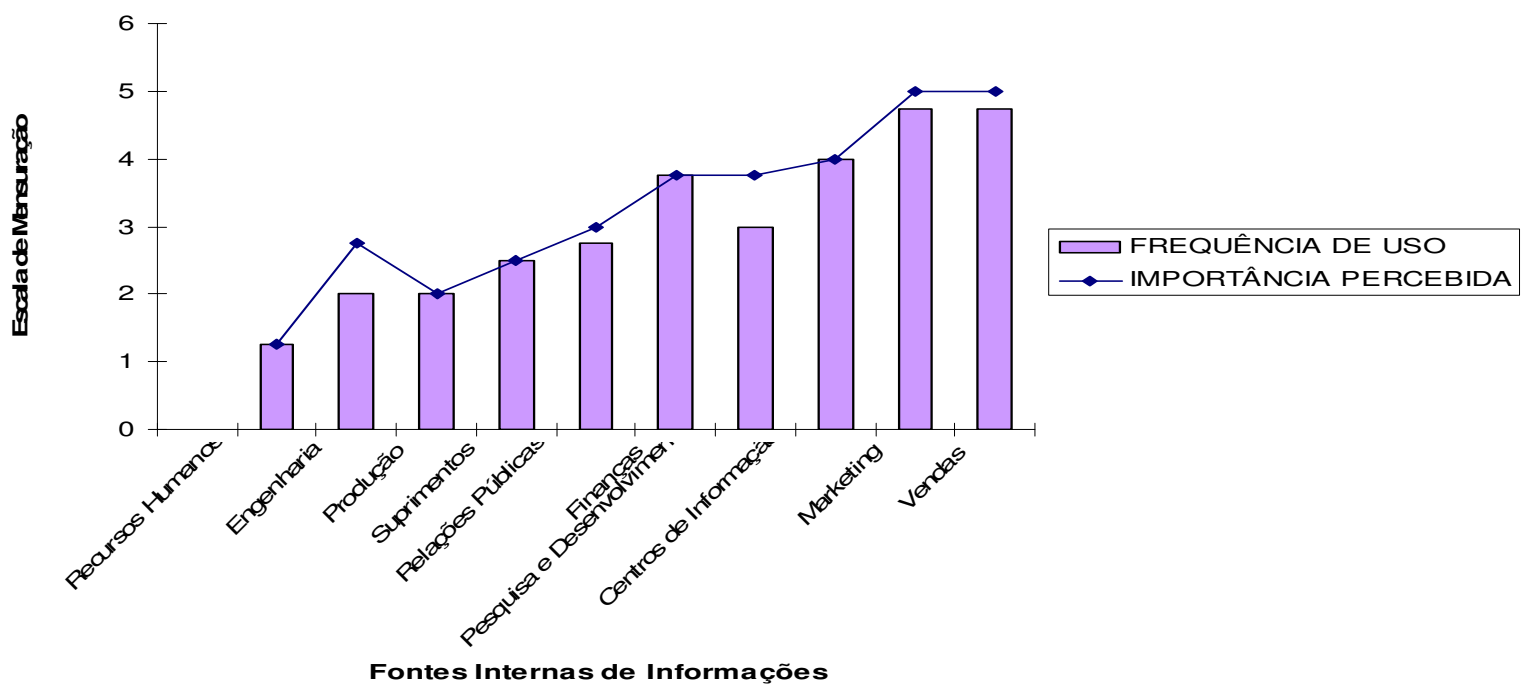

FIGURA 3 - Gráfico do grau de dependência informacional do departamento de inteligência de marketing, em relação aos demais departamentos da empresa ALFA.

Fonte: dados da pesquisa (TAB. 2 e 4). 
De acordo com a FIG. 3, percebe-se que os profissionais do departamento de inteligência de marketing têm grande dependência informacional, em relação aos departamentos de Marketing e de Vendas, seguidos, de perto, pelos departamentos de Finanças e Centros de Informação. Os departamentos de Pesquisa e Desenvolvimento, Relações Públicas apresentaram resultados intermediários. Por fim, os departamentos de Suprimentos, Produção, Engenharia e de Recursos Humanos foram os que apresentaram os menores resultados.

Em relação à alta dependência informacional dos profissionais de inteligência de marketing em relação aos departamentos de Marketing e de Vendas, pode-se afirmar, com certa propriedade, que esta dependência era esperada, uma vez que estes departamentos trabalham constantemente com os clientes da empresa. Assim, os profissionais de inteligência de marketing podem incentivar e treinar os funcionários destes departamentos no processo de coleta de dados e informações sobre desejos, necessidades e perfis dos clientes que negociam com a empresa ALFA, sejam eles pessoas físicas ou jurídicas.

Quanto à média dependência informacional dos profissionais de inteligência de marketing, em relação aos departamentos de Pesquisa e Desenvolvimento, Relações Públicas, Finanças e Centros de Informação, percebe-se que os departamentos de Finanças e Centros de Informação apresentaram resultados bastante significativos, o que era esperado pelos pesquisadores, uma vez que estes departamentos trabalham com 0 processamento de todos os dados e informações que circulam na empresa, sejam elas provenientes do ambiente interno ou externo. Pesquisa e Desenvolvimento e Relações Públicas também foram bem valorados pelos profissionais de inteligência de marketing, o que também era esperado, pela proximidade que estes departamentos têm com as necessidades e os desejos dos clientes, ou seja, estão orientados para o mercado consumidor. Por fim, os departamentos de Produção, Suprimentos, Engenharia e Recursos Humanos foram as fontes internas de informações que apresentaram menores graus de dependência informacional, o que não descarta a importância das mesmas para a geração de inteligências de marketing. Neste sentido, sugere-se a utilização de uma amostra maior para garantir a universalidade das conclusões apresentadas, especialmente em relação a estes últimos departamentos.

\section{Considerações finais, recomendações para futuras pesquisas e limitações}

O ambiente de negócios, do século XXI, tem exigido uma nova postura dos gestores contemporâneos, especialmente daqueles ligados às atividades de marketing. Fatores como globalização econômica, avanços tecnológicos, crises financeiras globais, mudanças políticas, ambientais e sociais (comportamento de compra dos consumidores) têm contribuído significativamente, para o aumento da complexidade e dinamicidade do 
ambiente onde as empresas atuam, independentemente dos seus tamanhos, formas legais, nacionalidades ou setores de atividades (OLIVEIRA, 2009). Entra-se em uma era determinada por incertezas, onde a sobrevivência e o crescimento das empresas, nos mercados em que atuam ao longo do tempo, dependerão, cada vez mais, das suas capacidades de processarem informações para a tomada de decisão eficaz, orientada para um ajuste rápido às crescentes ameaças e oportunidades impostas por seus ambientes em crescente transformação.

Nesta perspectiva, o presente artigo analisou o grau de dependência informacional dos profissionais de inteligência de marketing, em relação a determinadas fontes internas de informação. Para a consecução deste objetivo, foi adaptado o modelo de análise de dependência informacional desenvolvido por Oliveira (2009). Neste modelo, dois construtos são considerados: frequência de uso e importância percebida da fonte de informação para a consecução das atividades profissionais. Desta maneira, a partir da análise dos dados coletados, pode-se concluir que:

a) Os departamentos de Marketing e de Vendas foram as fontes que apresentaram os maiores graus de dependência informacional, conforme a percepção dos profissionais de inteligência de marketing da empresa ALFA;

b) Os departamentos de Finanças e Centros de Informações também apresentaram resultados significativos, em termos de fornecimento de informações para o desenvolvimento das atividades de inteligência de marketing;

c) Os departamentos de Pesquisa e Desenvolvimento e de Relações Públicas apresentaram resultados medianos, o que demanda pesquisas mais aprofundadas para comprovar estas conclusões;

d) Os departamentos ligados à área de produção da empresa ALFA (Engenharia, Produção e Suprimentos) apresentaram resultados pouco expressivos, o que também precisa ser melhor investigado por futuras pesquisas; e

e) O departamento de Recursos Humanos foi o que apresentou o menor resultado dentre todos os departamentos. Este fato era, até certo ponto, esperado pelos pesquisadores, uma vez que este departamento tem uma orientação mais para o ambiente interno e se relaciona pouco com os clientes da empresa ALFA.

Por último, como principal limitação deste estudo, está a impossibilidade de generalização dos resultados alcançados, uma vez que o critério de seleção da empresa ALFA foi não probabilístico (conveniência) e a estratégia de pesquisa utilizada foi o estudo de caso descritivo. Para futuras pesquisas, recomenda-se, então, a utilização de uma amostra maior de empresas (e de profissionais de inteligência de marketing), para garantir maior confiabilidade aos resultados alcançados, especialmente em relação às fontes internas de informação, que apresentaram graus pouco expressivos de dependência informacional, como foram os casos dos 
departamentos ligados à área de Produção e do departamento de Recursos Humanos do respectivo empreendimento.

\section{Referências}

BARBOSA, R. R. Uso de fontes de informação para a inteligência competitiva: um estudo da influência do porte das empresas sobre o comportamento informacional. Revista Eletrônica de Biblioteconomia e Ciência da Informação, Florianópolis, n. esp., p. 91-102, $1^{\circ}$ sem. 2006.

BARNEY, J. B.; CLARK, D. N. Resource-based theory: creating and sustaining competitive advantage. NY: Oxford University, 2007.

BARNEY, J. B.; HESTERLY, W. S. Administração estratégica e vantagem competitiva. São Paulo: Pearson Education, 2007.

BERGERON, P. Information resources management. Annual Review of Information Science and Technology - ARIST, v. 31. p. 263-300, 1996.

BORGES, M. E. N. A informação como recurso gerencial das organizações na sociedade do conhecimento. Ciência da Informação, v. 24, n. 2, 1995.

CHOO, C. W. A organização do conhecimento. São Paulo: SENAC São Paulo, 2003.

COLLIS, J.; HUSSEY, R. Pesquisa em Administração. 2a ed. Porto Alegre: Bookman, 2005.

DAFT, R.; LENGEL, R. Organizational information requirements, media richness and structural design. Management Science, v. 32, n. 4, p. 554571, May 1986.

D'AVENI, R. A. Hipercompetição: estratégias para dominar a dinâmica de mercado. Rio de Janeiro: Campus, 1995.

DAVENPORT, T. H.; PRUSAK, L. Working knowledge: how organisations manages what they know. Boston: Havard Business School Press, 1998.

DRUCKER, P. F. The information executives truly need. Harvard Business Review, Jan./Feb. 1995.

FULD, L. M. The new competitor intelligence: the complete resource for finding, analyzing, and using information about your competitors. New York: John Wiley \& Sons, 1995.

GREENWOOD, E. Metodologia de la investigacion social: Buenos Aires: Paidos, 1973.

GRZANKA, L. Competitive intelligence. Knowledge Management, v. 2, n. 4, p. 42-50, 1999.

HERRING, J. P. Key intelligence topics: a process to identify and define intelligence needs. Competitive Intelligence Review, v. 10, n. 2, p. 4-14, 1999. 
HITT, M. A., IRELAND, R. D.; HOSKISSON, R. E. Administração estratégica. São Paulo: Bookman, 2003.

JOHNSON, A. R. Your say: Competitive intelligence and knowledge management - two parts of the same whole. Knowledge Management Magazine, n. 3, v. 3, 1999.

KAHANER, L. Competitive intelligence: how to gather, analyze, and use information to move your business to the top. New York: Simon \& Schuster, 1996.

KOTLER, P. Administração de marketing: análise, planejamento, implementação e controle. 10a ed. São Paulo: Atlas, 2000.

LAVILLE, C.; DIONNE, J. A construção do saber: manual de metodologia da pesquisa em ciências humanas. Belo Horizonte: UFMG, 1999.

MARCHAND, D. A.; KETTINGER, W. J.; ROLLINS, J. D. Evolution of management thinking. In: __. Information orientation: the link to business performance. Oxford, New York: Oxford University Press, 2001. cap. 3. p.17-48.

MILLER, J. P. O milênio da inteligência competitiva. Porto Alegre: Bookman, 2002.

MINTZBERG, $\mathrm{H}$. et al. O processo da estratégia: conceitos e casos selecionados. 4. ed. Porto Alegre: Bookman, 2006.

OLIVEIRA, P. H. Proposta de uma metodologia para mensurar o nível de dependência do tomador de decisão em relação às fontes de informações: o caso dos pequenos varejos da região do Barro Preto em Belo Horizonte. Perspectivas em Ciência da Informação, v. 14, n.1, p. 209-229, 2009.

PEREIRA, F. C. M., BARBOSA, R. R. Uso de fontes de informação por consultores empresariais: um estudo junto ao mercado de consultoria de Belo Horizonte. Perspectivas em Ciências da Informação, v. 13, n. 1, p. 95-111, jan./abr. 2008.

PORTER, M. E. Competitive strategy: techniques for analyzing industries and competitors. New York, NY: The Free Press, 1980.

- Estratégia competitiva: técnicas para análise de indústria e da concorrência. Rio de Janeiro: Campus, 1985.

SAVIC, D. Evolution of information resource management. Journal of Librarianship and Information Science, v. 24, n. 3, p.127-138, Sep. 1992.

SIMON, H. Comportamento administrativo. Rio de Janeiro: FGV, 1971.

STAREC, C; GOMES, E.B.P; BEZERRA, J. (Orgs).Gestão estratégica da informação e inteligência competitiva. São Paulo: Saraiva, 2005.

YIN, R.K. Case study research: design and methods. Porto Alegre: SAGE Publications, 1994. 